\title{
(C) OPEN ACCESS Rapid diagnosis of pulmonary tuberculosis
and detection of drug resistance by combined
simultaneous amplification testing and reverse
dot blot
}

Yiwen Chen, ${ }^{1}$ Lahong Zhang, ${ }^{2}$ Liquan Hong, ${ }^{2}$ Xian Luo, ${ }^{2}$ Juping Chen, ${ }^{3}$ Leiming Tang, ${ }^{3}$ Jiahuan Chen, ${ }^{3}$ Xia Liu, ${ }^{2}$ Zhaojun Chen $^{2}$

${ }^{1}$ Hangzhou Normal University Affiliated Hospital (Clinical College), Hangzhou, China ${ }^{2}$ Clinical Laboratory Department, Hangzhou Normal University Affiliated Hospital, Hangzhou, China

${ }^{3}$ Tuberculosis Laboratory Department, Hangzhou Normal University Affiliated Hospital, Hangzhou, China

Correspondence to Professor Zhaojun Chen, Department of Clinical Laboratory, Hangzhou Normal University Affiliated Hospital, Hangzhou, Zhejiang Province 310015, China; hzczj2006@ 163.com

Received 3 August 2017 Revised 29 October 2017 Accepted 30 October 2017 Published Online First 14 November 2017
Check for updates

To cite: Chen Y, Zhang L, Hong L, et al. J Clin Pathol 2018:71:498-503.

\section{ABSTRACT}

Aims Making a correct and rapid diagnosis is essential for managing pulmonary tuberculosis (PTB), particularly multidrug-resistant tuberculosis. We aimed to evaluate the efficacy of the combination of simultaneous amplification testing (SAT) and reverse dot blot (RDB) for the rapid detection of Mycobacterium tuberculosis (MTB) and drug-resistant mutants in respiratory samples.

Methods 225 suspected PTB and 32 non-TB pulmonary disease samples were collected. All sputum samples were sent for acid-fast bacilli smear, SAT, culture and drug susceptibility testing (DST) by the BACTEC ${ }^{\text {TM }}$ MGIT $^{\text {TM }} 960$ system. 53 PTB samples were tested by both RDB and DNA sequencing to identify drug resistance genes and mutated sites.

Results The SAT positive rate (64.9\%) was higher than the culture positive rate $(55.1 \%)$, with a coincidence rate of $83.7 \%$. The sensitivity and specificity of SAT for diagnosing PTB were $66.7 \%$ and $100 \%$, respectively, while those for culture were $53.9 \%$ and $84.2 \%$, respectively. RDB has high sensitivity and specificity in identifying drug resistance genes and mutated sites. The results of RDB correlated well with those of DST and DNA sequencing, with coincidence rates of $92.5 \%$ and $98.1 \%$, respectively.

Conclusions The combination of SAT and RDB is promising for rapidly detecting PTB and monitoring drug resistance in clinical laboratories.

\section{INTRODUCTION}

The Mycobacterium tuberculosis (MTB) epidemic is a major health concern worldwide. The new global tuberculosis (TB) report from the WHO stated that approximately one-third of the world's population was infected with MTB. Furthermore, in 2015 there were an estimated 10.4 million new TB cases worldwide and approximately 1.4 million deaths, with China having the third highest number of TB patients in the world. ${ }^{1}$ With the widespread use of anti-TB drugs, multidrug-resistant tuberculosis (MDR-TB) and even extensively drug-resistant tuberculosis (XDR-TB) are now emerging and pose a considerable challenge to current TB prevention and control programs. ${ }^{2-4}$ Moreover, the number of inaccurate diagnoses and inappropriate treatments for TB patients are increasing, which encourages continued transmission of TB. Therefore, the rapid detection of TB and drug resistance both optimises treatment and improves outcomes and is also critical for reducing overall morbidity and mortality rates, which would greatly benefit public health.

Traditionally, MTB has been detected by acidfast bacilli (AFB) smear and the gold standard microbial culture and identification. ${ }^{5}$ However, these methods can have low sensitivity, are time consuming in routine clinical practice and require large amounts of bacteria. Developments in the field of molecular biology mean that nucleic acid amplification methods have better sensitivity and specificity for diagnosing TB than traditional diagnostic methods. ${ }^{7}$ In recent years, simultaneous amplification testing (SAT), which is a new-generation technology that uses isothermal RNA amplification and real-time fluorescence detection, has shown markedly higher sensitivity and specificity than other methods and has been widely used in various fields for detecting pathogens. ${ }^{89}$ Its excellent detection rate of smear-negative samples can decrease the number of inaccurate diagnoses.

Conventional drug susceptibility testing (DST) requires 3-8 weeks before the results are available, while rapid culture still takes an average of 7-9 days for smear-positive samples. However, this is sometimes too long in clinical practice. DNA sequencing for the identification of drug-resistant mutants is expensive and inconvenient in routine laboratory settings. In contrast, reverse dot blot (RDB) is rapid, sensitive, and has a high throughput, particularly for detecting gene mutations. RDB costs approximately US $\$ 40$ and includes four first-line anti-TB drugs. It can be used as a conventional method to replace sequencing, can simultaneously test for multidrug resistance and is widely applied in the field of molecular diagnostics. ${ }^{10} 11$

SAT has a higher sensitivity and is more accurate and rapid than traditional methods. ${ }^{12}{ }^{13}$ RDB can precisely and rapidly identify drug-resistance genes and mutated sites. In the present study, we aimed to evaluate the clinical value of combined SAT and RDB to rapidly diagnose pulmonary TB (PTB) and monitor drug resistance.

\section{MATERIALS AND METHODS}

\section{Sample collection}

Sputum samples were collected from patients screened at the Tuberculosis Department of 
Hangzhou Normal University Affiliated Hospital between October 2015 and October 2016. A total of 225 sputum samples were obtained from 225 different patients with suspected TB, including newly diagnosed and relapsed patients. In addition, 32 sputum samples were randomly collected from patients with respiratory disease in whom TB had been excluded (15 cases of community-acquired pneumonia, 10 of bronchial pneumonia and seven of bronchiectasis). All sputum samples were collected from patients in the early morning, and suspected TB sputum samples were consecutively collected before TB treatment.

\section{AFB smear and culture assays}

All sputum samples were routinely tested by AFB smear (Zhuhai BASO Biotechnology, China), culture and DST according to the WHO guidelines. ${ }^{14}$ Culture and DST were tested using the BACTEC ${ }^{\mathrm{TM}}$ MGIT $^{\mathrm{TM}} 960$ system (Becton Dickinson Diagnostic Systems, Sparks, MD). Mycobacterial identification was performed at the Center for Disease Control (CDC) in Hangzhou. All tests were carried out at the TB reference laboratory of Hangzhou Normal University Affiliated Hospital, according to the manufacturer's instructions and in accordance with the Chinese Laboratory Science Procedure of Diagnostic Bacteriology in Tuberculosis guidelines, ${ }^{15}$ with quality control routinely performed. Sputum samples were dissolved in $4 \%$ sodium hydroxide for 15-20 $\mathrm{min}$ at room temperature before they were tested using the BACTEC $^{\text {TM }}$ MGIT $^{\text {TM }} 960$ system.

\section{SAT for TB}

SAT (Shanghai Rendu Biotechnology, China) was performed for all 225 sputum samples, according to the manufacturer's instructions. Sputum samples were processed after they had been dissolved in $4 \%$ sodium hydroxide for $15-20 \mathrm{~min}$ at room temperature. All processed samples were centrifuged at $13000 \times \mathrm{g}$ for $5 \mathrm{~min}$, and the supernatant was discarded. A $50 \mu \mathrm{L}$ dilution solution was added for re-suspension. The M. tuberculosis inactivated strain $\mathrm{H} 37 \mathrm{Ra}$ (ATCC 25177) was used as a positive control, and double-distilled water as the negative control. Each sample, positive and negative control were placed in a $300 \mathrm{~W}$ water bath sonicator (Shanghai Shengyan Ultrasound Machines, China) for $15 \mathrm{~min}$ at room temperature. This was followed by centrifugation, and the supernatant was used as a template for SAT. For simultaneous RNA isothermal amplification, $2 \mu \mathrm{L}$ processed supernatant and $30 \mu \mathrm{L}$ reaction solution were prepared in a PCR tube. The mixture was pre-incubated at $60^{\circ} \mathrm{C}$ for $10 \mathrm{~min}$ and at $42^{\circ} \mathrm{C}$ for $5 \mathrm{~min}$. A $10 \mu \mathrm{L}$ aliquot containing 2000 units of Moloney murine leukaemia virus (M-MLV) reverse transcriptase and 2000 units of T7 RNA polymerase was then added. The solution was gently mixed and was immediately placed in a 7500 real-time PCR system (Applied Biosystems, Foster City, CA). Amplification was conducted at $42^{\circ} \mathrm{C}$ for $1 \mathrm{~min}$ for 40 cycles. FAM fluorescence data were collected after each amplification cycle. Samples with a cycle threshold $\left(\mathrm{C}_{\mathrm{T}}\right)$ of $\leq 35$ were classified as $\mathrm{TB}$ positive, while samples with $35<\mathrm{C}_{\mathrm{T}}<40$ were rechecked and were classified as TB positive if $\mathrm{C}_{\mathrm{T}}$ was $<40$, and as $\mathrm{TB}$ negative if $\mathrm{CT}$ was $\geq 40$.

\section{RDB}

RDB (Shenzhen Yaneng Biotechnology, China) was performed on 53 samples obtained from clinically diagnosed PTB patients, according to the manufacturer's instructions. All processed samples were centrifuged at $13000 \times \mathrm{g}$ for $5 \mathrm{~min}$, and the supernatant was discarded. A $50 \mu \mathrm{L}$ lysis buffer was added to the sediment, which was followed by incubation at $100^{\circ} \mathrm{C}$ for $10 \mathrm{~min}$

\begin{tabular}{|c|c|c|}
\hline Genes & Primers (sequences $5^{\prime} \rightarrow 3^{\prime}$ ) & Product size (bp) \\
\hline rрoB & $\begin{array}{l}\text { F (5'-ACGGTCGGCGAGCTGATCC-3') } \\
\text { R (5'-CAGACCGATGTTGGGCCCCT-3') }\end{array}$ & 351 \\
\hline katG & $\begin{array}{l}\text { F (5'-GACATTCGCGAGACGTTTCGG-3') } \\
\text { R (5'-GCTCTTAAGGCTGGCAATCTCG-3') }\end{array}$ & 469 \\
\hline inhA & $\begin{array}{l}\text { F (5'-CTATATCTCCGGTGCGGTCA-3') } \\
\text { R (5'-CTTGGCCATCGAAGCATAC-3') }\end{array}$ & 469 \\
\hline rpsL & $\begin{array}{l}\text { F (5'-AGGTCACGGCGTACATTCC-3') } \\
\text { R(5'-GCCCTTCTCCTTCTTAGCG-3') }\end{array}$ & 188 \\
\hline embB & $\begin{array}{l}\text { F (5'-TGATATTCGGCTTCCTGCTC-3') } \\
\text { R (5'-ACCGCTCGATCAGCACATAG-3') }\end{array}$ & 417 \\
\hline
\end{tabular}

embB, EMB mutant gene; katG and inhA, INH mutant gene; rpoB, RFP mutant gene; rpsL, SM mutant gene.

and centrifugation at $10000 \times \mathrm{g}$ for $2 \mathrm{~min}$. The supernatant was used as a template for RDB.

The PCR amplification programme comprised DNA amplification to yield a PCR mixture with a final volume of $25 \mu \mathrm{L}$ containing $4 \mu \mathrm{L}$ processed supernatant and $21 \mu \mathrm{L}$ reaction solution. PCR conditions were as follows: $50^{\circ} \mathrm{C}$ for $2 \mathrm{~min}, 95^{\circ} \mathrm{C}$ for $10 \mathrm{~min}, 30$ cycles of denaturation at $95^{\circ} \mathrm{C}$ for $45 \mathrm{~s}$ and annealing and extension at $68^{\circ} \mathrm{C}$ for $1 \mathrm{~min}, 30$ cycles of denaturation at $95^{\circ} \mathrm{C}$ for $30 \mathrm{~s}$ and annealing at $54^{\circ} \mathrm{C}$ for $30 \mathrm{~s}$ and extension at $68^{\circ} \mathrm{C}$ for $1 \mathrm{~min}$, and final extension at $68^{\circ} \mathrm{C}$ for $10 \mathrm{~min}$.

PCR products and membranes of immobilised probes were added to a $5 \mathrm{~mL}$ hybridization buffer A $(1 \times \mathrm{SSC}, 0.1 \% \mathrm{SDS})$, followed by denaturation at $100^{\circ} \mathrm{C}$ for $10 \mathrm{~min}$ and hybridization at $59^{\circ} \mathrm{C}$ for 1.5 hours. The membranes were washed by gentle shaking in $40 \mathrm{~mL}$ buffer $\mathrm{B}(0.5 \times \mathrm{SSC}, 0.1 \% \mathrm{SDS})$ for $15 \mathrm{~min}$ at $49^{\circ} \mathrm{C}$. The membranes were then incubated in an $8 \mathrm{~mL}$ streptavidin-peroxidase dilution $(1: 2000)$ at room temperature for 30 min. After being washed twice with the same buffer A for $5 \mathrm{~min}$, the membranes were then washed with buffer $\mathrm{C}(0.1$ $\mathrm{M}$ sodium citrate) for $2 \mathrm{~min}$. They were visualised by adding a colour substrate solution (tetramethyl benzidine) and kept in the dark for 5-10 min. The presence of clearly visible purple-blue spots on the membrane was considered to indicate a positive hybridization reaction.

\section{DNA sequencing}

Based on the study by Spinato et al, ${ }^{16}$ we designed five pairs of primers (table 1) to amplify regions of five genes associated with resistance to four anti-TB drugs: rifampicin (RFP), isonicotinic hydrazide (INH), streptomycin (SM) and ethambutol (EMB). The DNA template was purified using the TIANamp Virus DNA/ RNA Kit (Beijing Tiangen Biotech, China). The remainder of the supernatant that was used as a template in RDB was added to a solution containing $20 \mu \mathrm{L}$ proteinase $\mathrm{K}$ and $200 \mu \mathrm{L}$ carrier RNA before incubation at $56^{\circ} \mathrm{C}$ for $15 \mathrm{~min}$. Thereafter, the following steps were performed: addition of $200 \mu \mathrm{L}$ absolute ethanol, gentle mixing of the liquid solution, transfer to an absorbing column and centrifugation at $8000 \times \mathrm{g}$ for $1 \mathrm{~min}$, discarding of the waste liquid, addition of $500 \mu \mathrm{L}$ buffer GD and centrifugation for $1 \mathrm{~min}$, discarding of the waste liquid, addition of $600 \mu \mathrm{L}$ washing buffer PW and centrifugation for 1 min after letting the solution stand for $2 \mathrm{~min}$, discarding of the waste liquid, addition of $500 \mu \mathrm{L}$ absolute ethanol and centrifugation for $3 \mathrm{~min}$, discarding of the waste liquor, and elution of DNA into $30 \mu \mathrm{L}$ RNase-free water.

Purified DNA was amplified in a $10 \mu \mathrm{L}$ reaction mixture containing $1 \times$ buffer $(\mathrm{Mg} 2+$ plus), $200 \mu \mathrm{M}$ dNTP mixture, 
0.25 units DNA polymerase (PrimeSTAR HS), $0.2 \mu \mathrm{M}$ primer-F, $0.2 \mu \mathrm{M}$ primer-R and $3 \mu \mathrm{L}$ DNA template. PCR conditions were as follows: $50^{\circ} \mathrm{C}$ for $2 \mathrm{~min}$ and $95^{\circ} \mathrm{C}$ for $10 \mathrm{~min}, 30$ cycles of denaturation at $95^{\circ} \mathrm{C}$ for $45 \mathrm{~s}$ and annealing with extension at $68^{\circ} \mathrm{C}$ for $60 \mathrm{~s}, 30$ cycles of denaturation at $95^{\circ} \mathrm{C}$ for $30 \mathrm{~s}$ and annealing at $58^{\circ} \mathrm{C}$ for $30 \mathrm{~s}$ and extension at $68^{\circ} \mathrm{C}$ for $60 \mathrm{~s}$, and final extension at $68^{\circ} \mathrm{C}$ for $10 \mathrm{~min}$.

Agarose gel electrophoresis was performed, and the particular gene band was excised according to the required size of the gene. Purified PCR products were recovered by a DNA gel extraction kit (Beijing Tiangen Biotech, China). The resistance-determining region (rpoB, katG, inhA, rpsL, embB) was directly sequenced in an automated DNA sequencer by Hangzhou Qinke Biotech in China.

\section{Statistical analysis}

Statistical analysis was conducted using SPSS (version 18.0, SPSS, Chicago, IL). The sensitivity, specificity, positive predictive value (PPV) and negative predictive value (NPV) of SAT and culture were calculated. Categorical variables were analysed using the $\chi^{2}$ test. A P value of $\leq 0.05$ was considered statistically significant. Coincidence between SAT and culture data was assessed by Cohen's kappa test, with $\kappa \geq 0.75$ designated as excellent agreement, $0.4<\kappa<0.75$ as moderate agreement, and $\kappa<0.4$ as poor agreement. DST and DNA sequencing were used as standards to estimate the accuracy of RDB.

\section{RESULTS}

\section{Patient diagnoses}

Of the 225 patients with suspected TB, 219 were confirmed as having PTB and the remaining six as having non-TB mycobacteria (NTM) during their clinical follow-up. The diagnosis of PTB and NTM including bacteriology and radiography was based on guidelines for the treatment of TB by the WHO issued in $2010 .^{17}$

\section{Comparison between SAT and culture}

Among the 225 sputum samples from the suspected TB patients, the SAT positive rate was significantly higher than the culture positive rate $\left(64.9 \%, 146 / 225\right.$ vs $55.1 \%, 124 / 225, \chi^{2}=11.52$, $\mathrm{P}<0.05)$. The coincidence rate of SAT and culture was $83.7 \%$. A moderate level of agreement was found between the two methods $(\kappa=0.75)$, indicating suboptimal agreement (table 2$)$.

The sensitivity, specificity, PPV and NPV of SAT for diagnosing PTB were 66.7\% (146/219), 100\% (38/38), 100\% (146/146) and $34.2 \%(38 / 111)$, respectively, compared with corresponding values of $53.9 \%(118 / 219), 84.2 \%$ (32/38), 95.2\% (118/124) and $24.1 \%(32 / 133)$ for 960 culture. The sensitivity of SAT for

Table 2 Comparison of the coincidence rate between SAT and BACTEC $^{T M}$ MGIT $^{\text {TM }} 960$ culture for the detection of MTB

\begin{tabular}{|c|c|c|c|c|c|c|}
\hline & \multirow[b]{2}{*}{ SAT } & \multicolumn{2}{|c|}{ Culture } & \multirow{2}{*}{$\begin{array}{l}\text { Positive } \\
\text { coincidence } \\
\text { rate }\end{array}$} & \multirow{2}{*}{$\begin{array}{l}\text { Negative } \\
\text { coincidence } \\
\text { rate }\end{array}$} & \multirow{2}{*}{$\begin{array}{l}\text { Total } \\
\text { coincidence } \\
\text { rate }\end{array}$} \\
\hline & & + & - & & & \\
\hline \multirow[t]{2}{*}{ Total } & + & 114 & 32 & $91.9 \%$ & $75.9 \%$ & $83.7 \%$ \\
\hline & - & 10 & 101 & & & \\
\hline \multirow[t]{2}{*}{ Smear- positive } & + & 96 & 7 & $92.3 \%$ & $30.0 \%$ & $86.8 \%$ \\
\hline & - & 8 & 3 & & & \\
\hline \multirow[t]{2}{*}{ Smear- negative } & + & 18 & 25 & $90.0 \%$ & $79.7 \%$ & $81.1 \%$ \\
\hline & - & 2 & 98 & & & \\
\hline
\end{tabular}

MTB, Mycobacterium tuberculosis; SAT, simultaneous amplification and testing.

\begin{tabular}{|c|c|c|c|c|c|c|c|}
\hline \multirow{2}{*}{$\begin{array}{l}\text { Method } \\
\text { and group }\end{array}$} & \multirow[b]{2}{*}{ Result } & \multicolumn{2}{|c|}{$\begin{array}{l}\text { No. of patients with } \\
\text { a clinical diagnosis } \\
\text { of MTB }\end{array}$} & \multicolumn{4}{|c|}{ Mean (\%) } \\
\hline & & + & - & $\mathrm{Se}$ & Sp & PPV & NPV \\
\hline \multicolumn{8}{|l|}{ SAT } \\
\hline \multirow[t]{2}{*}{ All } & + & 146 & 0 & 66.7 & 100 & 100 & 34.2 \\
\hline & - & 73 & 38 & & & & \\
\hline \multirow{2}{*}{$\begin{array}{l}\text { Smear- } \\
\text { positive }\end{array}$} & + & 103 & 0 & 93.6 & 100 & 100 & 36.4 \\
\hline & - & 7 & 4 & & & & \\
\hline \multirow{2}{*}{$\begin{array}{l}\text { Smear- } \\
\text { negative }\end{array}$} & + & 43 & 0 & 39.4 & 100 & 100 & 34.0 \\
\hline & - & 66 & 34 & & & & \\
\hline \multicolumn{8}{|c|}{ BACTEC $^{\mathrm{TM}}$ MGIT $^{\mathrm{TM}} 960$ culture } \\
\hline \multirow[t]{2}{*}{ All } & + & 118 & 6 & 53.9 & 84.2 & 95.2 & 24.1 \\
\hline & - & 101 & 32 & & & & \\
\hline \multirow{2}{*}{$\begin{array}{l}\text { Smear- } \\
\text { positive }\end{array}$} & + & 100 & 4 & 90.9 & 0 & 96.2 & 0 \\
\hline & - & 10 & 0 & & & & \\
\hline \multirow{2}{*}{$\begin{array}{l}\text { Smear- } \\
\text { negative }\end{array}$} & + & 18 & 2 & 16.5 & 94.1 & 90.0 & 26.0 \\
\hline & - & 91 & 32 & & & & \\
\hline
\end{tabular}

MTB, Mycobacterium tuberculosis; NPV, negative predictive value; PPV, positive predictive value; SAT, simultaneous amplification and testing; Se, sensitivity; Sp, specificity.

diagnosing PTB was significantly higher than that of culture $\left(\chi^{2}=20.25, \mathrm{P}<0.05\right)$.

For smear-positive samples, the sensitivity of SAT was similar to that of culture $\left(93.6 \%, 103 / 110\right.$ vs $90.9 \%, 100 / 110, \chi^{2}=0.36$, $\mathrm{P}>0.05)$. For smear-negative samples, the sensitivity of SAT was significantly higher than that of culture $(39.4 \%, 43 / 109$ vs $16.5 \%, 18 / 109, \chi^{2}=23.04, \mathrm{P}<0.05$ ) (table 3).

\section{Performance of RDB, DST and DNA sequencing for the detection of the TB drug-resistance gene}

DST was performed on the sputum samples of 53 patients confirmed as having PTB. Nine isolates were drug-resistant strains, six of which were mono-resistant to RFP $(n=2)$, INH $(n=3)$ or EMB $(n=1)$, while three were MDR-TB to at least RFP and INH. In total, resistance was identified to RFP in five isolates, INH in six, SM in three, and EMB in two.

RDB was performed on the sputum samples of 53 patients confirmed as having PTB. All five (100\%) RFP-resistant isolates contained a mutation in the target region of the rpoB gene, four of the six (66.7\%) INH-resistant isolates contained mutations in the target region of the katG gene, all three (100\%) SM-resistant isolates contained mutations in the target region of the rpsL gene, and one of the two (50\%) EMB-resistant isolates had mutation in the embB gene. The mutations are showed in table 4. Using DST as the gold standard, RDB had a sensitivity of $77.8 \%(7 / 9)$ for the nine drug-resistant strains and a specificity of $95.5 \%(42 / 44)$ for the 44 drug-sensitive strains. The rate of agreement between RDB and DST was $92.5 \%$ (49/53).

Using DNA sequencing as the gold standard, RDB had a sensitivity of $87.5 \%(7 / 8)$ and a specificity of $100 \%(45 / 45)$. RDB and DNA sequencing results had an agreement rate of $98.1 \%$ $(52 / 53)$ (table 4).

\section{DISCUSSION}

TB infection is a major public health problem worldwide. The traditional culture method to detect TB often takes 3-8 weeks, and while a rapid culture system, such as BACTEC ${ }^{\mathrm{TM}} \mathrm{MGIT}^{\mathrm{TM}}$ 


\begin{tabular}{|c|c|c|c|}
\hline Strain no. & DST & RDB & DNA sequencing \\
\hline 1 & None & N1 missing & WT \\
\hline 1 & None & $306 \mathrm{~N}, 306 \mathrm{M}$ missing & WT \\
\hline 1 & $R, I, S, E$ & S531L, 43M, M306L & $\begin{array}{l}\text { S531L(TCG/TTG) } \\
\text { K43R(AAG/AGG) } \\
\text { M306L(ATG/GTG) }\end{array}$ \\
\hline 1 & I & WT & P388P(CCG/CCA) \\
\hline 1 & $\mathrm{R}$ & D516V, 15N, 15M missing & D516V(GAC/CCA) \\
\hline 1 & $\mathrm{R}, \mathrm{I}, \mathrm{S}$ & H526D, 315M, 88M & $\begin{array}{l}\text { H526D(CAC/GAC) } \\
\text { S315T(AGC/ACC) } \\
\text { K88R(AAG/AGG) }\end{array}$ \\
\hline 1 & $\mathrm{R}$ & H526D & H526D(CAC/AAC) \\
\hline 2 & I & $315 \mathrm{M}$ & S315T(AGC/ACC) \\
\hline 1 & $\mathrm{R}, \mathrm{I}, \mathrm{S}$ & S531L, 315M, 43M & $\begin{array}{l}\text { S531L(TCG/TTG) } \\
\text { S315T(AGC/ACC) } \\
\text { K43R(AAG/AGG) }\end{array}$ \\
\hline 1 & E & WT & WT \\
\hline 42 & None & WT & WT \\
\hline
\end{tabular}

DST, drug susceptibility testing; E, EMB-resistant; I, INH-resistant; MTB,

Mycobacterium tuberculosis; R, RFP-resistant; RDB, reverse dot blot; S, SM-resistant; WT, wild-type sequencing.

960, can hasten the detection process, results can still take an average of 7-9 days for smear-positive samples. ${ }^{18}$ This relatively long waiting period might contribute to less than optimal TB treatment. In developing countries, a rapid, simple, accurate and sensitive laboratory method that can be used to detect TB is urgently required.

In our study, we evaluated the clinical utility of SAT for suspected TB patients and demonstrated high sensitivity and specificity for all sputum samples. The sensitivity and specificity of SAT were significantly higher than those of culture, with a moderate agreement rate of $83.7 \%(\kappa=0.75)$. There were 32 clinically diagnosed PTB patients who were SAT-positive but culture-negative, which we attribute to the high sensitivity of SAT in clinical samples. The results of our study were consistent with those of Cui et al, ${ }^{12}$ which showed that SAT had $67.6 \%$ sensitivity and $100 \%$ specificity, with excellent agreement with culture $(\kappa=0.91)$.

SAT enables concurrent nucleic acid amplification and realtime fluorescence detection with the use of a special MTB isothermal RNA amplification primer and an optimised probe technology, with M-MLV polymerase and enhanced transcriptional activity of T7 RNA polymerase. SAT took only 4 hours to perform and specifically detected MTB, which addressed the limitation of traditional culture methods in differentiating between MTB and NTM. In our study, the sputum samples of six confirmed NTB patients were SAT-negative while all were positive in culture and identified as NTM by the CDC in Hangzhou. These findings suggested that SAT was both a sensitive test for diagnosing TB from sputum samples and also a tool that can raise suspicion of NTM lung disease in patients who are smear-positive and SAT-negative. ${ }^{13}$

Xpert MTB/RIF resistance PCR is a rapid and sensitive method that can detect DNA and has been extensively studied in resource-limited settings. SAT detects RNA, which is relatively more labile than DNA and quickly degrades after the pathogens die, and therefore is suitable for monitoring active TB and drug efficacy. In contrast, tests that previously targeted DNA detection were not fully utilised because of problems such as easy cross-contamination in the laboratory due to improper operation and inability to distinguish live from dead bacteria. ${ }^{19-21}$ SAT might reduce the risk of laboratory contamination and lower false-positive rates. ${ }^{13}$

However, in the present study, SAT yielded false-negative results in six patients, probably due to the presence of inhibitors of enzymatic amplification, suboptimal target extraction, low starting concentration, or uneven distribution of mycobacteria in the samples. ${ }^{22}$ However, the false-negative rate of SAT was lower than that of culture.

According to the worldwide estimates of the WHO, the median values of initial multidrug resistance and acquired multidrug resistance were $1.2 \%$ and $7.7 \%$, respectively, and there were an estimated 480000 new MDR-TB patients in $2016^{24}$. The rapid identification of drug-resistant MTB plays an important role in the diagnosis and treatment of TB patients. Previous studies have clearly shown the resistance mechanisms of first-line anti-TB drugs. Most resistance to RFP resulted from mutations in codons 516,526 and 531 of the rpoB gene encoding its RNA polymerase $\beta$ subunit. ${ }^{25}$ Among INH-resistant strains, 50\%-70\% had mutations in the katG gene, which reduced or inactivated the catalase-peroxidase activity of the drug, and 5\%-10\% had mutations in the inhA gene encoding enoyl-acyl carrier protein reductase. ${ }^{26}$ In SM-resistant strains, $64 \%-68 \%$ had a mutation in the rpsL gene encoding the ribosomal $30 \mathrm{~S}$ subunit of the S12 protein. $^{27}$ In EMB-resistant strains, $70 \%$ had a mutation in the embB gene encoding Arab transferase. ${ }^{28}$

In this study, DST was performed using the BACTEC ${ }^{\mathrm{TM}}$ MGIT $^{\text {TM }} 960$ system, but this gold standard needs at least 2 weeks for the results to become available. Sequence analysis is the gold standard for bacterial molecular identification ${ }^{29}$ but requires a relatively expensive automated sequencer and well-trained technicians, making its widespread application in clinical laboratories difficult.

RDB was developed for the rapid identification of drug-resistant genotypes and it took only 6-8 hours for the results to become available. It is a useful and inexpensive test for detecting most drug-resistant tuberculosis (DR-TB) isolates and can be routinely used in TB reference laboratories. ${ }^{30} \mathrm{RDB}$ uses specific biotin-modified primers to amplify related resistance genes. PCR products are then degenerated and modified with biotin, hybridised with a specific linear probe tagged on the membrane, and coloured by the biotin/peroxidase system, with final results based on the signal strength of spot hybridization.

Mokrousov et $a l^{11}$ reported the first attempt to combine different targets in a single assay for predicting anti-TB drug resistance. The reproducibility, sensitivity and specificity of RDB were superior to those of the routine phenotypic method reported by van Rie et al. ${ }^{31}$ Similarly, our study demonstrated good diagnostic performance for RDB, with coincidence rates of 92.4\% with DST and 98.1\% with DNA sequencing.

According to the RDB results,two drug-sensitive strains failed to show the correct colour dots, and the mutation probe dots were negative. These incorrect results might have been caused by less probe combination ability, inhibitor interference, or shorter chromogenic and hybridization time. Neither RDB nor DNA sequencing showed any mutations in the katG or inhA gene in one INH-resistant strain. This implied the possibility of other resistance mechanisms. Approximately 6\%-13\% of mutations in the ahpC gene encoding alkyl peroxide enzyme have been described. ${ }^{32}$ Therefore, the negative detection rate resulting from a lack of specific probes in frequent mutants can be easily corrected by adding appropriate probes on the membrane. ${ }^{33}$ One INH-resistant strain showed negative RDB results but had a silent mutation in katG gene codon 388 (CCG) 
CCA). It is unclear whether a similar mutation with a single base change can cause drug resistance. RDB and DNA sequencing did not show any changes in the embB gene in one EMB-resistant strain, but this was not unexpected as current literature showed that $30 \%$ of EMB-resistant strains do not have mutations in the embB gene. ${ }^{34}$ The results implied the existence of other resistance mechanisms or gene mutations in this group. Clinicians should assess these results in conjunction with the clinical situation. As the number of drug-resistant strains was limited in the present study, the frequencies of gene mutations cannot be further discussed. Nevertheless, our study demonstrated nine drug-resistant strains among 53 confirmed PTB patients (17.0\%), including three MDR-TB (5.7\%) patients, which accounted for $33.3 \%$ of the DR-TB patients. The resistant gene mutated types in our study covered the most commonly encountered examples. Future studies with more samples and gene mutations are required.

A high throughput test for MTB drug resistance testing is required in China and similar endemic areas. RDB can simultaneously detect several drug-resistant genes and significantly increases the detection rate of MDR strains, since it is a simple, rapid and reliable method for screening for TB, as DST is time consuming and DNA sequencing needs special and expensive equipment.

In summary, SAT is a sensitive, accurate and fast method for the direct detection of MTB in clinical settings, while RDB can rapidly screen DR-TB patients and detect gene mutations without the aid of expensive equipment. A combination of SAT and RDB is a promising tool for rapidly identifying PTB patients and monitoring drug resistance in clinical laboratories.

\section{Take home messages}

Simultaneous amplification testing (SAT) can rapidly detect Mycobacterium tuberculosis, and as the positive rate, sensitivity and specificity are higher than in traditional methods, it can reduce false-negative diagnoses.

- Reverse dot blot (RDB) is a useful and inexpensive test for the rapid identification of drug-resistant genotypes as it takes only 6-8hours, and has high coincidence rates with drug susceptibility testing and DNA.

- A combination of SAT and RDB is promising for rapidly diagnosing pulmonary tuberculosis and monitoring drug resistance in clinical laboratories.

\section{Handling editor Tony Mazzulli.}

Acknowledgements We thank Dr Qiang Ke and Dr Chengsong Cai for technical assistance and helpful discussions.

Contributors $Y C, X L, J C, L T, J C$ and $X L$ did the experiments. $Z C$ and $L H$ designed the study. YC and LZ wrote the manuscript. All authors read and approved the final manuscript.

Funding This work was supported by Hangzhou Science and Technology Development Plans (20140633B11) and Zhejiang Medical and Health Technology Program (2014ZDA018).

Competing interests None declared.

Patient consent Obtained.

Ethics approval The Ethics Committee of Hangzhou Normal University Affiliated Hospital, China.

Provenance and peer review Not commissioned; internally peer reviewed.

Open Access This is an Open Access article distributed in accordance with the Creative Commons Attribution Non Commercial (CC BY-NC 4.0) license, which permits others to distribute, remix, adapt, build upon this work non-commercially, and license their derivative works on different terms, provided the original work is properly cited and the use is non-commercial. See: http://creativecommons.org/ licenses/by-nc/4.0/

(C) Article author(s) (or their employer(s) unless otherwise stated in the text of the article) 2018. All rights reserved. No commercial use is permitted unless otherwise expressly granted.

\section{REFERENCES}

1. World Health Organization (WHO). Global Tuberculosis Report 2016 (WHO/HTM/TB/2016.13). Geneva, Switzerland:WHO. 2016.

2 Schön T, Miotto P, Köser CU, et al. Mycobacterium tuberculosis drug-resistance testing: challenges, recent developments and perspectives. Clin Microbiol Infect 2017; 23:154-60.

3 Dheda K, Chang KC, Guglielmetti L, et al. Clinical management of adults and children with MDR and XDR-TB. Clin Microbiol Infect 2016;23:131-40.

4 Gandhi NR, Nunn P, Dheda K, et al. Multidrug-resistant and extensively drug-resistant tuberculosis: a threat to global control of tuberculosis. Lancet 2010;375:1830-43.

5 Jiang LJ, Wu WJ, Wu H, et al. Rapid detection and monitoring therapeutic efficacy of Mycobacterium tuberculosis complex using a novel real-time assay. J Microbiol Biotechnol 2012;22:1301-6

6 Sethi S, Sethi SK, Singh S, et al. Evaluation of in-house loop-mediated isothermal amplification (LAMP) assay for rapid diagnosis of $M$. tuberculosis in pulmonary specimens. J Clin Lab Anal 2013;27:272-6.

7 Mdivani N, Li H, Akhalaia M, et al. Monitoring therapeutic efficacy by realtime detection of Mycobacterium tuberculosis mRNA in sputum. Clin Chem 2009;55:1694-700.

8 Fan L, Zhang Q, Cheng L, et al. Clinical diagnostic performance of the simultaneous amplification and testing methods for detection of the Mycobacterium tuberculosis complex for smear-negative or sputum-scarce pulmonary tuberculosis in China. Chin Med J 2014;127:1863-7.

9 Ling feng C, Liyun S, Peng S, et al. Detection of herpes simplex virus | RNA using simultaneous amplification and testing. Laboratory Medicine 2016;31:163-7.

10 Chen GF, Zhang CY, Wang YY, et al. Application of reverse dot blot hybridization to simultaneous detection and identification of harmful algae. Environ Sci Pollut Res Int 2015:22:10516-28.

11 Mokrousov I, Bhanu NV, Suffys PN, et al. Multicenter evaluation of reverse line blot assay for detection of drug resistance in Mycobacterium tuberculosis clinical isolates. J Microbiol Methods 2004; 57:323-35.

12 Cui Z, Wang Y, Fang L, et al. Novel real-time simultaneous amplification and testing method to accurately and rapidly detect Mycobacterium tuberculosis complex. J Clin Microbiol 2012;50:646-50.

13 Yan L, Tang S, Yang Y, et al. A large cohort study on the clinical value of simultaneous amplification and testing for the diagnosis of pulmonary tuberculosis. Medicine(Baltimore) 2016;95:e2597-5.

14 World Health Organization (WHO). Guidelines for surveillance of drug resistance in tuberculosis. $4^{\text {th }}$ ed. Geneva, Switzerland:WHO, 2009. (WHO/HTM/TB/2009/422).

15 Chinese Antituberculosis Association. Chinese laboratory science procedure of diagnostic bacteriology in tuberculosis: Chinese Antituberculosis Association, 1995:9-21.

16 Spinato J, Boivin É, Bélanger-Trudelle É, et al. Genotypic characterization of drug resistant Mycobacterium tuberculosis in Quebec, 2002-2012. BMC Microbiol 2016:16:164.

17 World Health Organization (WHO). Guidelines for treatment of tuberculosis 2010. $4^{\text {th }}$ ed. Geneva, Switzerland:WHO, 2010. (WHO/HTM/TB/2009.420).

18 Cruciani M, Scarparo C, Malena M, et al. Meta-analysis of BACTEC MGIT 960 and BACTEC $460 \mathrm{~TB}$, with or without solid media, for detection of mycobacteria. J Clin Microbiol 2004:42:2321-5.

19 Greco S, Girardi E, Navarra A, et al. Current evidence on diagnostic accuracy of commercially based nucleic acid amplification tests for the diagnosis of pulmonary tuberculosis. Thorax 2006;61:783-90.

20 Speers DJ. Clinical applications of molecular biology for infectious diseases. Clin Biochem Rev 2006;27:39-51.

21 Guerra RL, Baker JF, Alborz R, et al. Specimen dilution improves sensitivity of the amplified Mycobacterium tuberculosis direct test for smear microscopy-positive respiratory specimens. J Clin Microbiol 2008;46:314-6.

22 Jonas V, Alden MJ, Curry Jl, et al. Detection and identification of Mycobacterium tuberculosis directly from sputum sediments by amplification of rRNA. J Clin Microbiol 1993:31:2410-6.

23 Reischl U, Lehn N, Wolf $\mathrm{H}$, et al. Clinical evaluation of the automated COBAS AMPLICOR MTB assay for testing respiratory and nonrespiratory specimens. J Clin Microbiol 1998;36:2853-60

24 World Health Organization (WHO). WHO treatment guidelines for drug-resistant tuberculosis 2016 (WHO/HTM/TB/2016.4). Geneva, Switzerland: WHO, 2016.

25 Telenti A, Imboden P, Marchesi F, et al. Detection of rifampicin-resistance mutations in Mycobacterium tuberculosis. Lancet 1993;341:647-51.

26 Morlock GP, Metchock B, Sikes D, et al. ethA, inhA, and katG loci of ethionamideresistant clinical Mycobacterium tuberculosis isolates. Antimicrob Agents Chemother 2003;47:3799-805. 
27 Ramaswamy S, Musser JM. Molecular genetic basis of antimicrobial agent resistance in Mycobacterium tuberculosis. . Tuber Lung Dis 1998;79:3-29.

28 Ramaswamy SV, Amin AG, Göksel S, et al. Molecular genetic analysis of nucleotide polymorphisms associated with ethambutol resistance in human isolates of Mycobacterium tuberculosis. Antimicrob Agents Chemother 2000;44:326-36.

29 Xuegiong W, Junxian Z, Lixue C, et al. Identification of rifampin-resistant genotypes in Mycobacterium tuberculosis by PCR-reverse dot blot hybridization. Mol Biotechnol 2009:41:1-7.

30 Wu XQ, Lu Y, Zhang JX, et al. Detection of streptomycin resistance in Mycobacterium tuberculosis clinical isolates using four molecular methods in China. Yi Chuan Xue Bao 2006;33:655-63.
31 Van Rie A, Warren R, Mshanga I, et al. Analysis for a limited number of gene codons can predict drug resistance of Mycobacterium tuberculosis in a high-incidence community. J Clin Microbio 2001:39:636-41.

32 Slayden RA, Barry CE. The genetics and biochemistry of isoniazid resistance in Mycobacterium tuberculosis. Microbes Infect 2000;2:659-69.

33 Wu X, Zhang J, Chao L, et al. Identification of rifampin-resistant genotypes in Mycobacterium tuberculosis by PCR-reverse dot blot hybridization. Mol Biotechnol 2009:41:1-7.

34 Johnson $\mathrm{R}$, Jordaan AM, Pretorius $\mathrm{L}$, et al. Ethambutol resistance testing by mutation detection. Int J Tuberc Lung Dis 2006;10:68-73. 